\title{
Phantom word activation in L2
}

\author{
Mirjam Broersma ${ }^{\mathrm{a}}$, Anne Cutler ${ }^{\mathrm{b}, \mathrm{c}, *}$

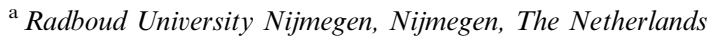 \\ ${ }^{\mathrm{b}}$ MPI for Psycholinguistics, Nijmegen, The Netherlands \\ ${ }^{\mathrm{c}}$ MARCS Auditory Laboratories, University of Western Sydney, Australia
}

Received 7 June 2007; received in revised form 2 September 2007; accepted 14 November 2007

\begin{abstract}
L2 listening can involve the phantom activation of words which are not actually in the input. All spoken-word recognition involves multiple concurrent activation of word candidates, with selection of the correct words achieved by a process of competition between them. L2 listening involves more such activation than L1 listening, and we report two studies illustrating this. First, in a lexical decision study, L2 listeners accepted (but L1 listeners did not accept) spoken non-words such as groof or flide as real English words. Second, a priming study demonstrated that the same spoken non-words made recognition of the real words groove, flight easier for L2 (but not L1) listeners, suggesting that, for the L2 listeners only, these real words had been activated by the spoken non-word input. We propose that further understanding of the activation and competition process in L2 lexical processing could lead to new understanding of L2 listening difficulty.

(C) 2007 Elsevier Ltd. All rights reserved.
\end{abstract}

Keywords: Word recognition; Activation; Competition; Listening; L1; L2; Phantom words

\section{Introduction}

It is an odd feature of the L2 listening literature that relatively little research attention has been accorded to the most central aspect of spoken-language processing: the recognition of words. On the one hand, there is an extensive literature on the perception

\footnotetext{
* Corresponding author. Address: MPI for Psycholinguistics, PO Box 310, 6500 AH Nijmegen, The Netherlands.

E-mail addresses: mirjam.broersma@mpi.nl (M. Broersma), anne.cutler@mpi.nl (A. Cutler).
} 
and production of L2 phonemes, and a range of theoretical models of processing at this level (Best, 1995; Flege, 1995). This topic is important for understanding linguistic systems and their inter-relations, and for determining the limits of plasticity of the human processing system; thus it is understandable that it has attracted so much research attention. For the analysis of L2 listening in natural situations, however, it is far from directly applicable. On the other hand, there are claims that most important of all in the L2 situation is the use of context; efficient use of context enables L2 listeners to compensate for imperfections in lower-level processing (e.g., Chiang and Dunkel, 1992; Long, 1990). This too is an important research topic (indeed, not only in L2 listening); but this too fails to provide a useful analysis of L2 listening and its problems.

Translating the phonetic findings into recommendations for the teaching of L2 listening is complicated by two factors. First, word recognition (in L1 or L2) is never solely determined by phoneme recognition. Every listener has to cope with misperception due to, for instance, background noise; and every listener has to cope with homophonic forms. These situations have to be resolved by reference to the context, because the phonetic level simply does not provide enough information for correct resolution. Therefore every listener has in place mechanisms for using context to compensate for phonetic inadequacy, and these mechanisms are of course fully available to the L2 listener. It is impossible for an L1 listener to tell whether lain or lane has been heard except by using knowledge of the context in which they occur; if an L2-English listener misperceives the difference between $/ \mathrm{r} /$ and $/ 1 /$, then the same mechanisms can be called upon to determine whether what was heard was lain, lane, rain or reign. Second, apparent phoneme perception performance often mismatches with listening performance in real speech, in both directions: poor phonetic discrimination with good sentence-level performance, or good discrimination in phonetic-level tasks with poor performance on word recognition involving the same contrasts. This is known as the "scaling-up" problem (Bradlow, 2007). Thus it is dangerous to assume a direct relation between phonetic discrimination and overall listening performance.

Translating the findings on contextual processing in L2 into recommendations for the teaching of L2 listening is similarly problematic. "Context" is not a unitary phenomenon; as Field (2004) has argued in this journal, the term is used to refer to many sources of knowledge at widely differing levels of processing. Lexical, syntactic, semantic, prosodic, discourse and pragmatic processing, even visual and gestural processing - all can be lumped under the term "context", though each type of processing taps into different knowledge sources and thus would potentially require quite different training techniques. The pedagogy of L2 listening is not served by such over-general concepts; the development of effective training must be based on empirical evidence providing precise analyses of the stages of L2 listening.

In particular, effective analysis of context requires analysis of the individual role of lexical items. While it is possible to construct example sentences which the listener might seem to be able to understand without much in the way of lexical processing (Would you be so kind as to pass me the water, combined with pointing to a water glass), real word examples abound in which each individual word is indispensable (Chew two yellow pills before breakfast). Word recognition is the central component of language processing; there is no sentence without the words comprising it, and phonemic contrast only occurs because it distinguishes words.

Intensive research in L1 listening over the past two decades has resulted in significant increases in our understanding of the process of spoken-word recognition (for a review, 
see McQueen, 2007). As has been repeatedly demonstrated in the laboratory, speech input immediately activates potential word candidates concurrently (Moss et al., 1997; Zwitserlood, 1989), and these candidates compete with one another for recognition (Goldinger et al., 1992; McQueen et al., 1994). Words rarely occur in isolation, and word boundaries in continuous speech are rarely explicit, so the potential candidates can even be the end of one word plus the beginning of the next (Tabossi et al., 1995). Thus when a listener hears the phrase what a strange act, there is temporary but discernible activation not only of the words which were actually spoken, but also of other words supported by the input, both within the actual words (stray, train, ray, range, etc.) and across them (is, jack, jacked). This multiple simultaneous consideration of potential options for what the input might be is apparently quicker and more efficient than waiting around to see what the full input actually is, because listeners certainly do not wait.

In our laboratory over the past few years, we have explored many aspects of the word recognition process in L2 listening. Most of our experiments are run with highly proficient listeners, a uniquely informative population; briefly, if a problem in L2 listening shows up with these listeners, one can be fairly sure that it is an intransigent problem which will be observed with less proficient listeners as well. With such listeners, we have observed, for instance, activation of the L1 vocabulary in a situation in which only the L2 was spoken and only the L2 was relevant - confronted with a display containing among other things a desk and a lid, and instructed to look at the desk, Dutch participants also look at the lid (because a lid in Dutch is a deksel, which begins in the same way as desk; Weber and Cutler, 2004). With an even more proficient population (German interpreters of English), we have observed that the relative likelihood of phoneme sequences in their L1 ( $s h l$ - is a very likely word beginning in German but not in English) affects their L2 listening (Weber and Cutler, 2006).

Particularly important for L2 listening is determining how much activation and competition occurs, because even though multiple activation and competition is clearly an efficient process for recognizing words, it is undeniably true that more competitors means slower word recognition (Norris et al., 1995; Vroomen and De Gelder, 1995). Consider, first, the potential increase that could be caused by pseudo-homophones. As described above, if not only rain and reign, but also rain and lane are stored in the L2 listener's lexicon as homophones, occurrence of any one of them will activate all of them for this listener. Experiments show that this is so; for any listener, L1 or L2, repetition of the same word (e.g., light-light) will lead to faster responses on the second occurrence, but for L2 listeners, a succession of pseudo-homophones can lead to faster responses to the second. Specifically, Japanese listeners recognize light faster if they heard write earlier and Dutch listeners recognize kettle faster if they heard cattle earlier (Cutler and Otake, 2004).

In fact, however, analysis of the English vocabulary suggests that this effect will not be as serious as might be expected. The number of pseudo-homophones such as lane/rain caused by inability to discriminate /r/ from /1/ in the English vocabulary is about 300 (Cutler, 2005); pseudo-homophones involving vowel confusions, such as cattle/kettle, are even less numerous. Given that English contains so many homophones anyway, the increase in competition due to pseudo-homophones of this kind is probably negligible.

Nonetheless, L2 listening is highly likely to involve significantly more competition than L1 listening. All vocabularies contain tens or hundreds of thousands of separate words, made up from only a few dozen phonemes. This means that words must resemble one another, and long words mostly contain short words embedded within them. Above we 
described how words are temporarily but discernibly activated when they are fully embedded in longer words (e.g., ray in range), or are partially supported and as yet not disambiguated (rake and range simultaneously activated), and how this causes competition. Both types of competition are likely to be significantly exacerbated for L2 as compared to L1 listeners, because the same perceptual confusions which result in pseudohomophones will activate words which seem to be embedded in or supported by the input. Thus if range occurs in the input, it will activate not only ray but also lay, and it will have to be disambiguated from lake as well as from rake. These "phantom" competitors are activated alongside the competitors that the L1 listener would activate. Accordingly, the L2 listener experiences more competition.

In a series of studies, we have examined the activation of phantom words in L2 listening. The experiments described in the present paper exemplify our approach. With the goal of precise analysis of the L2 listening process, we focus in each case on a specific type of L1-L2 mismatch which could produce phantom words. Here we report the case of phantom activation of, say, groove or flight given a spoken input such as groof or flide. The contrast between voiced and voiceless sounds in word-final position occurs in English but not in Dutch, although Dutch allows exactly the same contrast in initial positions, and Dutch listeners can very accurately perceive the difference in nonsense syllables such as coof/coove where no English lexical minimal pairs are available (Broersma, 2005a). In a lexical decision experiment we first asked the baseline question: is input such as groof indeed perceived as a word by these L2 listeners? In a second experiment, using a priming task, we then asked the crucial question: does automatic activation of phantom words occur in the kind of contexts in which listeners naturally encounter input such as groof? Each experiment compared the L2 listeners' performance with that of L1 listeners given the same input.

\section{Experiment 1: lexical decision}

\subsection{Method}

Participants were 24 native Dutch-speaking Nijmegen University students and 24 native British English-speaking Birmingham University students. Dutch participants had received on average eight (minimally six) years of English in primary and secondary schooling.

Materials were 32 monosyllabic English words ending with /z/, /s/, /v/, /f/, /b/, /p/, /d/ or $/ \mathrm{t} /$. The words had high frequency (mean CELEX (Baayen et al., 1995) log frequency: 1.99 per million) and did not sound like existing Dutch words. For each word, a "nearword" was formed by replacing voiced final consonants with voiceless or vice versa (e.g., groove to * groof, flight to *flide). Eighty-four monosyllabic English filler words and 84 possible non-words made up the rest of the presented materials; these varied in phonological form, so that the crucial contrast in the experimental items would not be obvious to participants. The materials were recorded by a male native speaker of British English.

Procedure: participants heard all 84 filler words and 84 filler non-words, but only one form (real word or near-word) of each experimental item. Thus there were two versions of the experiment, each heard by $12 \mathrm{~L} 1$ and $12 \mathrm{~L} 2$ listeners. Stimuli were presented over closed headphones, one at a time in random order. Participants were tested one at a time in a quiet room. Written instructions in their native language asked them to decide for 


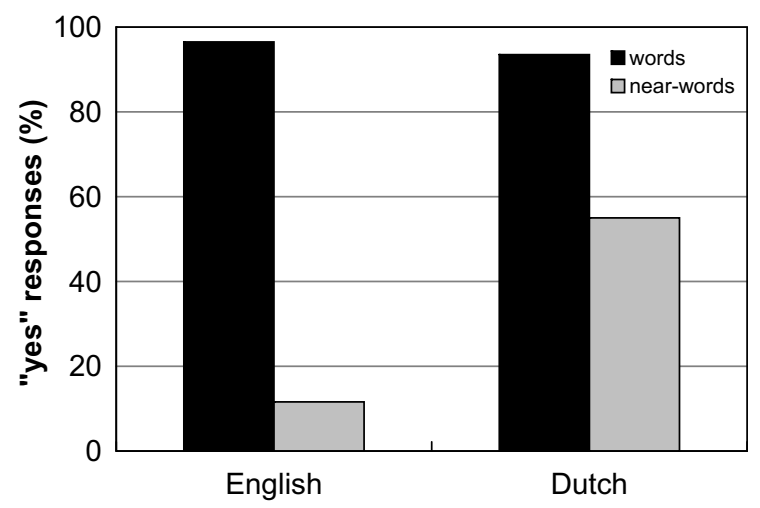

Fig. 1. Experiment 1: English and Dutch listeners' percentage of "yes" responses to words and near-words.

each heard item whether it was an existing English word, and to indicate their decision with a button-press, as rapidly and as accurately as possible.

\subsection{Results and discussion}

Fig. 1 shows the percentage of words and near-words accepted as a word ("yes" responses). One item (ship-shib) was excluded from the analysis due to an error in the item lists. L1 and L2 listeners' results were not significantly different for the real words (L2: 94\% "yes", L1: 97\%) or for the non-words (L2: 10\%, L1 12\%), but, as the figure clearly shows, they were very different for the near-words $(F 1(1,46)=74.37, p<.001 ; F 2(1,30)=56.11$, $p<.001$ ). The direction of change from real to near-word was irrelevant (both groof-type and flide-type near-words received 55\% "yes" responses). These lexical decision results have thus clearly established the baseline phenomenon: Dutch listeners to English consider near-words such as groof to be real words more often than L1 listeners do.

\section{Experiment 2: lexical activation}

In real life, isolated near-words such as those presented in this study rarely occur; L2 listeners need not in general expect utterances such as groof or flide from native speakers. But they will nonetheless frequently encounter near-words in running speech, embedded in other words (rup in rupture) or across them (groof in big roof). As described above, it is in these locations that multiple activation of possible interpretations of the input is the norm, that they can cause a significant increase in competition. In Experiment 2 we examined whether utterances such as big roof could indeed cause phantom activation of words such as groove.

We used the experimental method most commonly used to measure lexical activation: cross-modal priming. In this task, participants hear a spoken input (the prime), and press a button to signal whether a visual input (the target) corresponds to an actual word. The method exploits one of the most robust lexical effects there is: people respond faster and more accurately when they process something they have just processed before. Thus faster button-press responses to groove after hearing big roof constitute evidence that big roof activated groove. Again, we compare the L2 listeners' performance to that of L1 listeners. 


\subsection{Method}

Participants were 36 native Dutch speakers and 36 native British English speakers, none of whom had participated in Experiment 1; the L1 participants were in this case from the University of Sussex.

Materials were based on those of Experiment 1. The same 32 real words served as visual targets. For the auditory primes, words and corresponding near-words were recorded embedded in two words, spanning a word boundary. For each item, an appropriate two-word carrier context was found; e.g., halF LIGHT and halF LIED for the word and near-word pair flight-flide. Words and near-words were then excised from their carrier contexts to serve as auditory stimuli (e.g., flight was excised from halF LIGHT and flide from halF $L I E D)$. For each item: in the match condition the prime was the excised real word, in the mismatch condition the prime was the excised near-word, and in the control condition the prime was a monosyllabic word or non-word phonologically and semantically unrelated to the target. Activation can be measured by comparing responses in the match and mismatch condition with responses in the control condition.

There were also 227 monosyllabic filler targets: 98 words and 129 non-words, with equal numbers of match, mismatch, and control primes. The primes for the filler word and non-word targets were also made from two-word fragments. All carrier fragments were recorded by the same native speaker of British English as in Experiment 1.

Procedure: participants were tested one at a time in a quiet room. They received written instructions, in their native language, to decide as rapidly and as accurately as possible whether the visually presented item was an existing English word. They were also instructed to attend to the spoken input. The auditory primes were presented over closed headphones and the visual targets on a computer screen in front of the participants, with the target appearing exactly at offset of the prime. Responses were timed from appearance of the target; no time limit was applied to these responses. Each participant received each of the 32 experimental targets only once, with match, mismatch, and control conditions counterbalanced as closely as possible. The fillers were arranged so that across the experiment as a whole, each participant heard half word and half non-word primes, and saw half word and half non-word targets; and further, that the word status of the prime could not predict the word status of the target. There were at most five real-word or five nonword targets in succession, and two experimental targets were separated by at least one filler item. Both reaction time (RT) and percent correct responses were measured.

\subsection{Results and discussion}

In the crucial experimental items, visual targets were always real words, so that the correct response was always "yes". For both L2 and L1 listeners, matching primes should facilitate recognition of the visual target (e.g., flight-FLIGHT). Thus, the proportion of correct responses should be higher and/or the RTs of the correct responses should be shorter in the match condition than in the control condition (care-FLIGHT). Further, if near-words caused more lexical activation for L2 than for L1 listeners, in the mismatch condition (flide-FLIGHT) there should be more facilitation for Dutch than for English listeners (as compared to the control condition). Fig. 2 shows exactly this pattern.

Statistical analyses compared the match and mismatch conditions separately with the control condition (across participants $-F 1$ - and across items - F2). For the L1 listeners, 


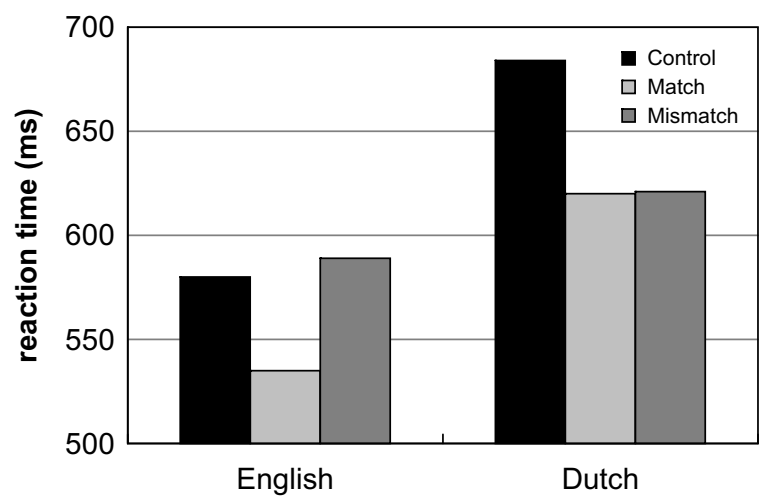

Fig. 2. Experiment 2: English and Dutch listeners' mean reaction times of correct responses in the control, match, and mismatch condition.

the responses were significantly faster after a matching prime than after a control prime $(F 1(1,35)=24.33, p<.001 ; F 2(1,30)=15.01, p<.001)$, indicating that the matching prime had activated the same lexical item as the visual target had. For these listeners, the RTs after mismatching and control primes, however, did not differ $(F 1(1,35)<1$; $F 2(1,30)<1)$, indicating that the mismatching prime had not activated the target word. For the L2 listeners, the match prime also produced significant facilitation ( $F 1$ $(1,34)=11.68, p<.01 ; F 2(1,30)=9.12, p<.01)$, and the mismatching prime did too $(F 1(1,34)=16.29, p<.001 ; F 2(1,30)=13.35, p<.001)$.

Table 1 shows the English and Dutch listeners' percentage of correct responses and the RTs of the correct responses in the three conditions, separately for the words with voiced $(+\mathrm{V})$ and voiceless $(-\mathrm{V})$ endings. The pattern of the percentage of correct responses showed a similar pattern to that observed with the RTs for the L2 listeners: the match prime produced facilitation $(F 1(1,35)=4.02, p<.053 ; F 2(1,30)=7.97, p<.01)$ and so did the mismatching prime $F 1(1,35)=5.2, p<.05 ; F 2(1,30)=10.46, p<.01)$. For the L1 listeners, virtually all responses were correct, as Table 1 shows, so that differences between conditions in percentage correct were insignificant.

As the Table further shows, the amount of mismatch RT priming for the L2 listeners was greater for the voiced-final targets than for the voiceless-final targets; nevertheless,

Table 1

Experiment 2: English and Dutch listeners' percentage of correct responses and RTs of correct responses for target words in control, match, and mismatch condition, separately for target words with voiced $(+\mathrm{V})$ or voiceless final consonants $(-\mathrm{V})$

\begin{tabular}{|c|c|c|c|c|c|}
\hline \multirow[t]{2}{*}{ Target word } & \multirow[t]{2}{*}{ Condition (prime) } & \multicolumn{2}{|c|}{ Correct $(\%)$} & \multicolumn{2}{|l|}{$\mathrm{RT}(\mathrm{ms})$} \\
\hline & & English & Dutch & English & Dutch \\
\hline \multirow[t]{3}{*}{ +V (groove) } & Control (spend) & 98.4 & 85.9 & 588 & 719 \\
\hline & Match (groove) & 99.0 & 91.1 & 540 & 652 \\
\hline & Mismatch (groof) & 98.4 & 91.1 & 608 & 622 \\
\hline \multirow[t]{3}{*}{$-\mathrm{V}($ flight $)$} & Control (care) & 97.9 & 84.3 & 572 & 648 \\
\hline & Match (flight) & 99.0 & 92.2 & 531 & 589 \\
\hline & Mismatch (flide) & 96.4 & 93.2 & 570 & 620 \\
\hline
\end{tabular}

Examples are given in brackets. 
the pattern was highly similar for both item types, and the proportion of correct responses across condition for the two item types was virtually identical.

Thus the cross-modal priming results confirm the pattern that the lexical decision results suggested might occur. The pronunciation of near-words such as groof in real speech contexts such as big roof is just as capable of activating groove for a L2 listener as the isolated form groof. These contexts cause phantom word activation for L2 listeners, while L1 listeners experience no such effect.

\section{General discussion}

Phantom words are activated in L2 listening. Sequences of sounds in spoken input activate more potential word candidates, and activate them longer, for L2 listeners than they do for L1 listeners. The experiments reported here show that this happens for near-words which differ from real words in a word-final phonological feature; in other experiments, we have shown similar effects for near-words which differ from real words in vowels (Broersma, 2005b), and we have shown prolonged ambiguity resulting from vowel similarity (with Dutch L1, English L2; Weber and Cutler, 2004) and consonant similarity (with Japanese L1, English L2; Cutler et al., 2006). The lexical decision task which we used as our baseline measure has produced the same kind of evidence in experiments with even very closely related L1 and L2 (with Spanish L1, Catalan L2; Pallier et al., 2001; Sebastián-Gallés et al., 2005). The phenomenon is clearly a widespread one, affecting L2 listening across different levels of language relationship and listener proficiency.

The case study we used here is particularly informative in that the phantom word activation obviously does not arise because of simple inability of L2 listeners to perceive a phonetic contrast between L2 sounds. The voiced-voiceless contrast (/d/-/t/, /v/-/f/, etc.) appears in our listeners' L1, Dutch, as well as in English. In Dutch, it does not appear in word-final position. Nonetheless, Dutch listeners perform very well in simple phonetic tasks with nonsense syllables such as coof, coove (Broersma, 2005a, 2008); in fact, when vowel length correlates of the contrast are removed, these L2 listeners actually show greater sensitivity to the phonetic distinction than L1 listeners do. (This is because English listeners usually rely on the vowel length differences - longer vowels in coove than in cooffor making word-final distinctions, whereas Dutch listeners use the phonetic cues that are also operative in word-initial position.) Despite this exquisite sensitivity when asked to perform a phonetic task, the same listeners are beset by phantom activation when they hear near-words differing from real words in only this feature. Not only strings pronounced in isolation (groof) induce this phantom activation, but also real-speech strings containing the same sequences (big roof).

Phantom word activation is a serious issue because, as described in the Introduction, all spoken-word recognition involves multiple activation and competition. These are natural and efficient processes which presumably operate in the same way in all listeners; so just as unknown words often activate the nearest known words for L2 listeners (Field, 2004), so do non-words temporarily activate the nearest words for L1 listeners (e.g., Newman et al., 1997; Taft, 1986). But the crucial difference between the L1 and the L2 cases is the speed with which such temporary activation can be suppressed. Although competition is in principle a highly efficient mechanism for rapid processing of multiply ambiguous signals such as speech, the more competition there is and the longer it persists, the more slowly words are recognized (Norris et al., 1995; Vroomen and De Gelder, 1995). Listening is thus a 
constant process of adjusting the competitor population as evaluation of the incoming input allows.

Near-words, as we called them, are rapidly rejected by the L1 listener; in a cross-modal priming experiment, they leave no measurable trace of activation of their real-word neighbours at all (Marslen-Wilson et al., 1995; Soto-Faraco et al., 2001). For the L2 listener, however, evaluation of the incoming input does not usually lead to efficient rejection; in consequence, phantom lexical candidates engage in the competition, and the listener's processing of the input will inevitably be slower.

Thus it is probable that a significant component of the difference in difficulty between L1 and L2 listening is located at the lexical level. As we noted in the Introduction, the literature which is specifically devoted to L2 listening has accorded proportionally greater attention to levels below (phonetic) and above (contextual) the word than to the lexical level itself. The literature on language transfer (e.g., Clyne, 2003; Odlin, 1989; Weinreich, 1953) similarly concentrates on the aspects of language structure where great differences between L1 and L2 systems can cause the learner significant problems of adjustment: the phonetic repertoire, the prosodic structure, the morphology, syntax, and semantics. The lexicon is not generally considered to present transfer problems of the same magnitude. Our findings suggest that this is true; L2 listening operates at the lexical level with exactly the same processes of multiple activation and competition as are appropriate for the L1.

Ironically, however, the problems we have identified arise just because of this parallelism. Small perceptual confusions at the phonetic level may lead to an explosion of extra competition at the lexical level just because of the efficiency with which every possible lexical candidate is activated.

Although the great attention to phonetic processing in the L2 listening literature has resulted in substantial understanding of processes at that level, we have argued that the research findings in that area do not translate directly to the natural listening situation. Our present findings, as noted, provide further evidence that phonetic processing does not directly predict listening difficulty. There is a growing body of similar evidence. Consider, for instance, the well-attested fact that L2 listening becomes disproportionately difficult under noisy conditions. Even though no L2 user needs to be convinced that this phenomenon is real, every 10 years or so science demonstrates it in the laboratory anyway (Gat and Keith, 1978; Mayo et al., 1997; Náblek and Donahue, 1984). Recent research has shed new light on the source of the added difficulty. When the speech recognition task is reduced to simple phonetic identification (meaningless consonant-vowel or vowel-consonant syllables), and all contextual support is removed (even including temporal predictability of speech onset), then addition of noise affects L1 and L2 listening equivalently (Cutler et al., 2004). This suggests that the performance difference in more natural situations is due not to greater effects of noise on the L2 listeners' processing operations, but to greater ability of the L1 listeners to recover from noise effects. There are undoubtedly a good number of components of this ability, but one of them is knowledge of words. Van Wijngaarden et al. (2002) showed that a measure of linguistic entropy - letter-by-letter guessing of visually presented words in text - predicted how accurately L2 listeners would identify L2 speech presented in noise.

It is clear, therefore, that greater attention needs to be paid to the lexical level in modeling L2 processing. We would also call for more empirical research focusing specifically on L2 word recognition in natural situations. And finally, we propose that routes to improvement of L2 listening may also be found at the lexical level. Three points in particular arise from the evidence we have presented. 
First, it is important to bear in mind that a learner's knowledge of a given word is not the same as ability to recognize it accurately or confidently when it occurs in speech (and to reject, as L1 listeners would, minimally different near-words). Accurate identification of true realisations of the same words in different possible contexts is one potential training route.

Second, it is similarly important to bear in mind that distinguishing homophones is probably not the most significant L2 listening problem. Distinguishing real occurrences of a given word from occurrences that are spurious (embedded in or across other words) or minimally variant (near-words) is what will make the difference in real life.

Third, we stress that activation is ultimately determined by support from the spoken input. The extent to which a phantom word is activated may be less than a true occurrence of the same word would achieve. The more similar words a listener knows, the more they will constrain how any given word should be realized. In short, the larger the L2 listener's L2 vocabulary, the more they may be able to avoid phantom word activation.

\section{Appendix Experimental. stimuli used in Experiments 1 and 2}

Words from Experiment 1 served as match primes in Experiment 2, near-words as mismatch primes. In Experiment 2, match primes also served as visual targets.

\begin{tabular}{|c|c|c|c|c|c|}
\hline \multicolumn{3}{|l|}{ Primes: } & \multicolumn{3}{|c|}{ Carrier fragments: } \\
\hline $\begin{array}{l}\text { Match } \\
\text { (words) }\end{array}$ & $\begin{array}{l}\text { Mismatch } \\
\text { (near-words) }\end{array}$ & Control & Match & Mismatch & Control \\
\hline $\begin{array}{l}\mathrm{v} / \\
\text { dive } \\
\text { groove } \\
\text { move } \\
\text { shave }\end{array}$ & $\begin{array}{l}\text { dife } \\
\text { groof } \\
\text { moof } \\
\text { shafe }\end{array}$ & $\begin{array}{l}\text { spend } \\
\text { spend } \\
\text { fres } \\
\text { fres }\end{array}$ & $\begin{array}{l}\text { good ivy } \\
\text { big rooves } \\
\text { calm Oovington } \\
\text { posh aviator }\end{array}$ & $\begin{array}{l}\text { good eyeful } \\
\text { big roofs } \\
\text { calm Oofington } \\
\text { posh aphid }\end{array}$ & $\begin{array}{l}\text { Swiss pendant } \\
\text { Swiss pendant } \\
\text { safe rescue } \\
\text { safe rescue }\end{array}$ \\
\hline $\begin{array}{l}\text { /f/ } \\
\text { dwarf } \\
\text { laugh } \\
\text { scarf } \\
\text { stiff }\end{array}$ & $\begin{array}{l}\text { dwarve } \\
\text { lauve } \\
\text { scarve } \\
\text { stiv }\end{array}$ & $\begin{array}{l}\text { prup } \\
\text { prup } \\
\text { prup } \\
\text { spend }\end{array}$ & $\begin{array}{l}\text { bad warfare } \\
\text { until after } \\
\text { ox calf } \\
\text { least iffy }\end{array}$ & $\begin{array}{l}\text { bad war victim } \\
\text { until Arvin } \\
\text { does the ox calve } \\
\text { east Ivrea }\end{array}$ & $\begin{array}{l}\text { sharp rupture } \\
\text { sharp rupture } \\
\text { sharp rupture } \\
\text { Swiss pendant }\end{array}$ \\
\hline $\begin{array}{l}\text { /z/ } \\
\text { cheese }\end{array}$ & cheece & friend & much easier & much Easter fun & $\begin{array}{l}\text { brief } \\
\text { rendering }\end{array}$ \\
\hline news & newce & friend & does Lynn use & in use & $\begin{array}{l}\overline{\text { brief }} \\
\text { rendering }\end{array}$ \\
\hline $\begin{array}{l}\text { phrase } \\
\text { praise }\end{array}$ & $\begin{array}{l}\text { phrace } \\
\text { praice }\end{array}$ & $\begin{array}{l}\text { crup } \\
\text { friend }\end{array}$ & $\begin{array}{l}\text { safe raise } \\
\text { sharp raise }\end{array}$ & $\begin{array}{l}\text { safe race } \\
\text { sharp race }\end{array}$ & $\begin{array}{l}\text { weak rupture } \\
\text { brief } \\
\text { rendering }\end{array}$ \\
\hline $\begin{array}{l}\text { /s/ } \\
\text { choice } \\
\text { kiss }\end{array}$ & $\begin{array}{l}\text { choise } \\
\text { kiz }\end{array}$ & $\begin{array}{l}\text { crup } \\
\text { cup }\end{array}$ & $\begin{array}{l}\text { reach Oice Lake } \\
\text { weak ischial joint }\end{array}$ & $\begin{array}{l}\text { reach Oise Lake } \\
\text { weak Israel }\end{array}$ & $\begin{array}{l}\text { weak rupture } \\
\text { weak upside }\end{array}$ \\
\hline
\end{tabular}


Appendix (continued)

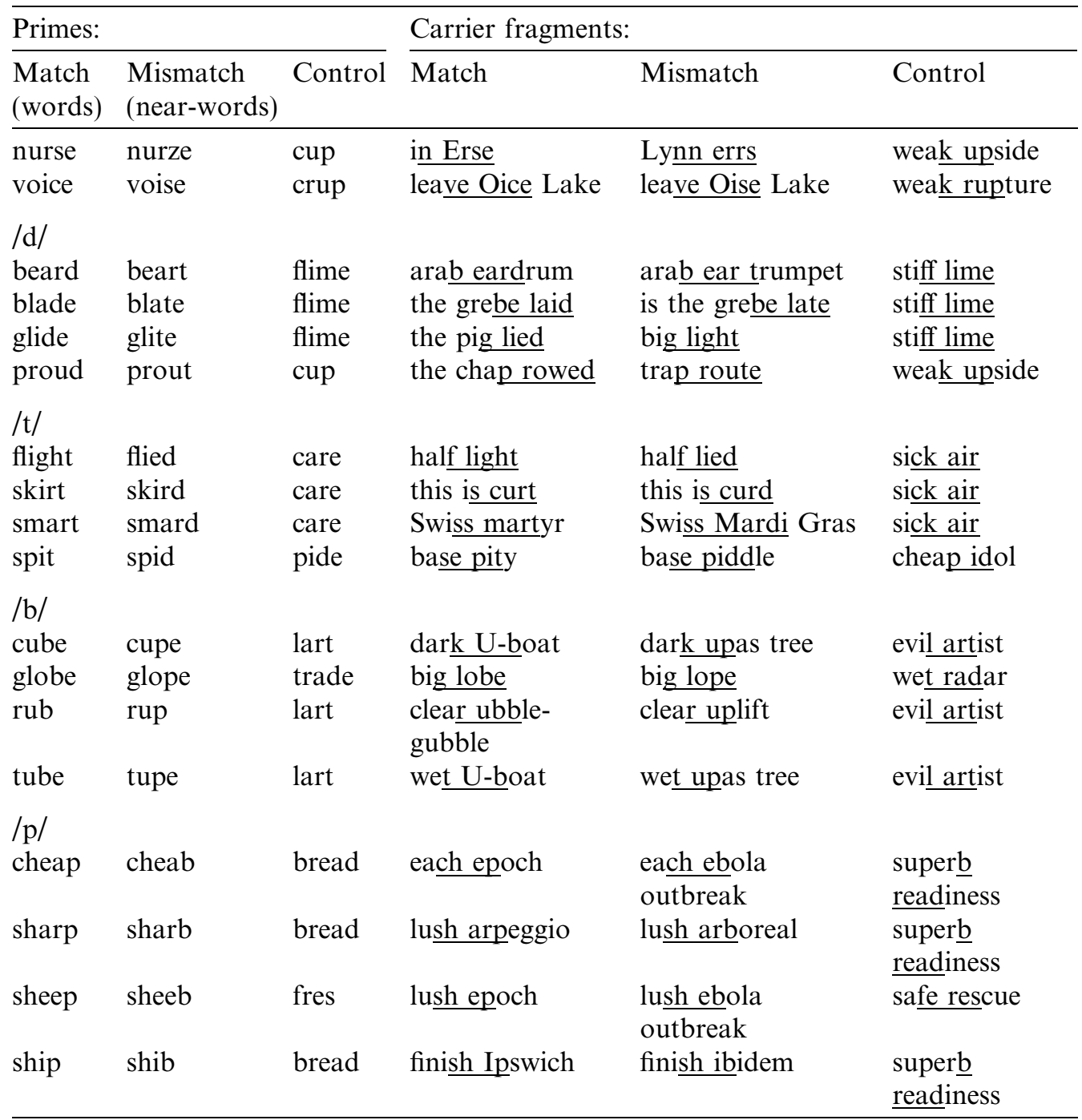

\section{References}

Baayen, H., Piepenbrock, R., Gulikers, L., 1995. The CELEX Lexical Database (CD-ROM). Linguistic Data Consortium, University of Pennsylvania, Philadelphia, PA.

Best, C.T., 1995. A direct realist view of cross-language speech perception. In: Strange, W. (Ed.), Speech Perception and Linguistic Experience: Issues in Cross-language Research. York Press, Baltimore, pp. 171204.

Bradlow, A., 2007. Information flow and plasticity across levels of linguistic sound structure: responses to the target papers by Cutler \& Weber and by Goldinger. In: Proceedings of the International Congress of Phonetic Sciences (ICPhS XVI), Saarbrücken, Germany, pp. 55-58.

Broersma, M., 2005a. Perception of familiar contrasts in unfamiliar positions. Journal of the Acoustical Society of America 117, 3890-3901. 
Broersma, M., 2005b. Phonetic and lexical processing in a second language. PhD Dissertation. Radboud University Nijmegen, Nijmegen, The Netherlands.

Broersma, M., 2008. Flexible cue use in nonnative phonetic categorization. Journal of the Acoustical Society of America, 123.

Chiang, C.S., Dunkel, P., 1992. The effect of speech modification, prior knowledge, and listening proficiency on EFL lecture learning. TESOL Quarterly 26, 345-374.

Clyne, M., 2003. Dynamics of Language Contact: English and Immigrant Languages. Cambridge University Press, Cambridge.

Cutler, A., 2005. The lexical statistics of word recognition problems caused by L2 phonetic confusion. In: Proceedings of Eurospeech 2005 (Ninth European Conference on Speech Communication and Technology), Lisbon, September 2005.

Cutler, A., Otake, T., 2004. Pseudo-homophony in non-native listening. Paper Presented to the 75th Meeting of the Acoustical Society of America, New York.

Cutler, A., Weber, A., Smits, R., Cooper, N., 2004. Patterns of English phoneme confusion by native and nonnative listeners. Journal of the Acoustical Society of America 116, 3668-3678.

Cutler, A., Weber, A., Otake, T., 2006. Asymmetric mapping from phonetic to lexical representations in secondlanguage listening. Journal of Phonetics 34, 269-284.

Field, J., 2004. An insight into listeners' problems: too much bottom-up or too much top-down? System 32, $363-$ 377.

Flege, J.E., 1995. Second language learning: theory, findings, and problems. In: Strange, W. (Ed.), Speech Perception and Linguistic Experience: Issues in Cross-language Research. York Press, Baltimore, pp. 233272.

Gat, I.B., Keith, R.W., 1978. An effect of linguistic experience. Audiology 17, 339-345.

Goldinger, S.D., Luce, P.A., Pisoni, D.B., Marcario, J.K., 1992. Form-based priming in spoken word recognition: the roles of competition and bias. Journal of Experimental Psychology: Learning, Memory, and Cognition 18, 1211-1238.

Long, D.R., 1990. What you don't know can't help you. Studies in Second Language Acquisition 12, 65-80.

Marslen-Wilson, W., Nix, A., Gaskell, G., 1995. Phonological variation in lexical access: abstractness, inference and English place assimilation. Language and Cognitive Processes 10, 285-308.

Mayo, L.H., Florentine, M., Buus, S., 1997. Age of second-language acquisition and perception of speech in noise. Journal of Speech and Hearing Research 40, 686-693.

McQueen, J.M., 2007. Eight questions about spoken-word recognition. In: Gaskell, G. (Ed.), The Oxford Handbook of Psycholinguistics. Oxford University Press, Oxford, pp. 37-53.

McQueen, J.M., Norris, D., Cutler, A., 1994. Competition in spoken word recognition: spotting words in other words. Journal of Experimental Psychology: Learning, Memory, and Cognition 20, 621-638.

Moss, H.E., McCormick, S.F., Tyler, L.K., 1997. The time course of activation of semantic activation during spoken word recognition. Language and Cognitive Processes 10, 121-136.

Nábĕlek, A.K., Donahue, A.M., 1984. Perception of consonants in reverberation by native and non-native listeners. Journal of the Acoustical Society of America 75, 632-634.

Newman, R.S., Sawusch, J.R., Luce, P.A., 1997. Lexical neighborhood effects in phonetic processing. Journal of Experimental Psychology: Human Perception and Performance 23, 873-889.

Norris, D., McQueen, J.M., Cutler, A., 1995. Competition and segmentation in spoken-word recognition. Journal of Experimental Psychology: Learning, Memory, and Cognition 21, 1209-1228.

Odlin, T., 1989. Language Transfer. Cambridge University Press, Cambridge.

Pallier, C., Colomé, A., Sebastián-Gallés, N., 2001. The influence of native-language phonology on lexical access: exemplar-based versus abstract lexical entries. Psychological Science 12, 445-449.

Sebastián-Gallés, N., Echeverría, S., Bosch, L., 2005. The influence of initial exposure on lexical representation: comparing early and simultaneous bilinguals. Journal of Memory and Language 52, 240-255.

Soto-Faraco, S., Sebastián-Gallés, N., Cutler, A., 2001. Segmental and suprasegmental mismatch in lexical access. Journal of Memory and Language 45, 412-432.

Tabossi, P., Burani, C., Scott, D., 1995. Word identification in fluent speech. Journal of Memory and Language $34,440-467$.

Taft, M., 1986. Lexical access codes in visual and auditory word recognition. Language and Cognitive Processes 1, 297-308.

Van Wijngaarden, S., Steeneken, H., Houtgast, T., 2002. Quantifying the intelligibility of speech in noise for nonnative listeners. Journal of the Acoustical Society of America 111, 1906-1916. 
Vroomen, J., De Gelder, B., 1995. Metrical segmentation and lexical inhibition in spoken word recognition. Journal of Experimental Psychology: Human Perception and Performance 21, 98-108.

Weber, A., Cutler, A., 2004. Lexical competition in non-native spoken-word recognition. Journal of Memory and Language 50, 1-25.

Weber, A., Cutler, A., 2006. First-language phonotactics in second-language listening. Journal of the Acoustical Society of America 119, 597-607.

Weinreich, U., 1953. Languages in Contact: Findings and Problems. Mouton, The Hague.

Zwitserlood, P., 1989. The locus of the effects of sentential-semantic context in spoken-word processing. Cognition 32, 25-64. 